\title{
La vida de Castruccio Castracani: un exemplum de innovación en la tradición republicana
}

\author{
Gabriela RoDRÍGUEZ
}

Recibido: 5 de septiembre de 2012.

Aceptado: 20 de marzo de 2013.

\section{RESUMEN}

En este artículo se analiza la biografía que Niccolò Machiavelli dedicó a un condotiero de la ciudad de Lucca y a la que dio el título de La vita di Castruccio Castracani. A partir de este texto, se aborda no solo la figura de Castracani como exemplum del príncipe nuevo y sus virtudes; también se explora hasta qué punto sus argumentos favorecen una lectura diferente de la relación entre el liderazgo personal y la democracia. Tomando como eje esta obra de Machiavelli generalmente ignorada por la crítica especializada, proponemos un concepto de gobierno popular que opera como forma representativa de una democracia que se legitima en la novedad y es encarnada por una figura personal, siempre dentro del republicanismo maquiaveliano.

\section{PALABRAS CLAVE}

Machiavelli, república, democracia, gobierno popular.

\begin{abstract}
This paper analyses a biography written by Niccolò Machiavelli of a condottiero of the city of Lucca, entitled The Life of Castruccio Castracani. Delving into this book, the main objective of this article is to study Castracani as an exemplar of the new prince and his virtues, while also exploring the possibility of a different reading of the relationship between personal leadership and democracy. This work by Machiavelli has generally been ignored by specialists; yet it offers a concept of popular government that can function as a representative form of a democracy legitimized by novelty, incarnated by an individual while remaining within the republican matrix of the Machiavellian approach.
\end{abstract}

\section{KEYWORDS}

Machiavelli, republic, democracy, popular government. 


\section{INTRODUCCIÓN: ACTUALIDAD DE UNA HERMENÉUTICA}

El análisis presentado en este artículo se enmarca en una investigación más amplia centrada en la relación conceptual entre democracia y república y sus usos en la Teoría Política clásica (antigua y moderna) y contemporánea ${ }^{1}$. En ese recorrido hemos analizado corpus textuales y contextos intelectuales de diversa índole, abordando desde teóricos políticos canónicos hasta referentes del pensamiento político latinoamericano y, en particular, del pensamiento argentino del siglo diecinueve. Sin embargo, nuestro objetivo siempre fue, por un lado, iluminar una relación conceptual desde una perspectiva diacrónica pero informada sincrónicamente a partir de momentos conceptuales ${ }^{2}$; y por el otro, proponer conceptualizaciones que fueran interesantes no solamente para el trabajo hermenéutico sobre determinados textos y conceptos, sino también para la Teoría Política contemporánea y el análisis político de los problemas de nuestro tiempo ${ }^{3}$.

Es el mismo ejercicio que nos proponemos hacer con Niccolò Machiavelli (1469-1527) y su biografía de Castruccio Castracani (1281-1328) ${ }^{4}$. Más allá de la diferencia taxonómica entre repúblicas y principados establecida en el capítu-

${ }^{1}$ Esta investigación ha sido realizada tanto de forma individual, en mis sucesivos planes de trabajo como investigadora del Consejo Nacional de Investigaciones Científicas y Técnicas de Argentina (CONICET), como desde la coordinación de un grupo sobre "República y Republicanismo", compuesto por becarios e investigadores en formación.

${ }^{2}$ Contamos con la referencia a los textos ya clásicos de John G. A. Pocock o de Pierre Rosanvallon, donde un momento conceptual, de la república o la democracia, se relaciona con un teórico de referencia. John Greville Agard Poсоск, El momento maquiavélico. El pensamiento florentino y la tradición republicana atlántica, Tecnos, Madrid, 2008. Pierre Rosanvallon, Le moment Guizot, Éditions Gallimard, Paris, 1985. Más allá de estas obras, nuestra definición de momento conceptual se alinea con la de Gonzalo Capellán de Miguel: "Así cuando nos referimos a un momento conceptual de un concepto X (por ejemplo 'el momento sociológico de la opinión pública') estamos postulando un tipo ideal que nos permite comprender con más claridad un material empírico complejo al que asignamos perfiles definidos en la comparación con otras circunstancias anteriores o posteriores a la misma serie...En principio, parece que el momento conceptual define la clase de todos los momentos conceptuales que como herramientas hermenéuticas se utilizarán en la historia de los conceptos". Gonzalo CAPELLÁn DE Miguel, "Los momentos conceptuales. Una nueva herramienta para el estudio de la semántica histórica", en Javier Fernández SebASTIÁn y Gonzalo CAPellán De Miguel (eds.), Lenguaje, tiempo y modernidad. Ensayos de historia conceptual, Colección Pensamiento histórico, Globo Editores, Chile, 2011, p. 115.

${ }^{3}$ Véase por ejemplo: Gabriela RodRíGUEZ, "Una república en disputa contra sí misma: el legado de nuestros antepasados para la Argentina del Bicentenario": Revista Argentina de Ciencia Politica, n. ${ }^{\circ}$ 13-14 (2010-2011), pp. 55-91.

${ }^{4}$ Edición en italiano: Niccolò MaChIAVELLI, "La vita di Castruccio Castracani", en Corrado Vivanti (ed.), Opere de Niccolò Machiavelli, vol. III, Einaudi, Torino, 2005. Edición en español: 
lo II de El Príncipe (1532) ${ }^{5}$, el republicanismo maquiaveliano reivindica tanto el poder popular (por ejemplo, su superior capacidad para juzgar liderazgos y opciones políticas que garanticen tanto la estabilidad del stato o su "institucionalidad"6) como el principado en su carácter de condición de posibilidad de la unidad italiana. La vita di Castruccio Castracani (1520) opera no solamente como un exemplum de esta tensión maquiaveliana entre república, institucionalidad, participación popular, novedad y liderazgo personal sino también de un tipo particular de republicanismo que no puede ser fácilmente asimilado con la concepción moderna de gobierno representativo.

En tal sentido, postulamos una categoría que, si bien aparece en Machiave$11 i^{7}$, es más rica si se la piensa con Machiavelli: el gobierno popular. Esta noción se transforma no solo en una herramienta para abordar el republicanismo maquiaveliano desde la díada novedad-institución sino en un concepto que interpela a las teoría modernas y contemporáneas de la democracia desde sus tensiones y contradicciones.

En esta hipótesis de lectura sobre La vida de Castruccio Castracani y en esta apuesta conceptual por el gobierno popular han influido dos debates teóricos distintos pero, en algún sentido, complementarios: el republicano y el populista.

Por un lado, si bien la hermenéutica conceptual de la Escuela de Cambrid$\mathrm{ge}^{8}$ es fundamental en nuestro planteo, disentimos de la interpretación predomi-

Nicolás Maquiavelo, La vida de Castruccio Castracani, Editorial Quadrata, Buenos Aires, 2006. Uno de los motivos de tomar este texto de Machiavelli como objeto de análisis se debió al poco interés que ha recibido en la crítica especializada, especialmente entre los teóricos políticos. Con la excepción de los textos de Peter Bondanella, más cercano sin embargo a la teoría literaria, o de Joseph C. Macfarland, que referimos en este trabajo, los maquiavelistas clásicos, tradicionales o contemporáneos, casi ni lo nombran. Peter Bondanella, "Castracani: Machiavelli’s Archetypal Prince": Italica, vol. 49 (1972); Joseph C. MacFARLAND, "Machiavelli's Imagination of Excellent Men: An Appraisal of the Lives of Cosimo de' Medici and Castruccio Castracani": American Political Science Review, vol. 93, n. ${ }^{\circ} 1$ (1999).

${ }^{5}$ Edición en italiano: Niccolò Machiavelli, Il Principe, Metalibri, Milano, 2009. Edición en español: Nicolás MaQuiaVelo, El Príncipe, Espasa, Madrid, 1997.

${ }^{6}$ Véase Nicolás Maquiavelo, Discursos sobre la primera década de Tito Livio, Alianza, Madrid, 2000, pp. 42-45, 306-307, 361.

${ }^{7}$ Machiavelli se ocupa de las formas de gobierno popular en los Discursos y las identifica con la estructura institucional de la Roma Antigua, el régimen de Girolamo Savonarola (14521498) en Florencia y, en menor medida, con el gobierno republicano de Pier Soderini (1450-1522) del cual el mismo Machiavelli fue segundo secretario de la cancillería. Ibid., pp. 86-92, 146-147, 167, 313-314.

${ }^{8}$ El representante por antonomasia de la Escuela de Cambridge sería Quentin Skinner ya que, estrictamente hablando, John G. A. Pocock pertenece a la Escuela de Saint Louis; una escuela que en el contexto de la historiografía estadounidense se diferencia de la Escuela de Harvard represen- 
nante en muchos de los neorrepublicanos como John G. A. Pocock, Philip Pettit ${ }^{9}$ o Maurizio Viroli ${ }^{10}$, que ven a Machiavelli como un defensor del vivere civile y de una república institucionalmente estática y aristocrática. Esta concepción deriva, como bien puntualiza John McCormick ${ }^{11}$, en una visión conservadora de las instituciones maquiavelianas que activan el poder popular, y termina siendo funcional a la interpretación liberal representativa (madisoniana) de la democracia y la república ${ }^{12}$. A pesar de estar de acuerdo con esta crítica de McCormick, tampoco nos resulta convincente su propuesta de reemplazar al Machiavelli republicano elitista por uno democrático populista.

De este nuestro punto de vista consideramos que el sentido de la "república" en el autor de los Discursos y en otros republicanos clásicos y modernos no se reduce exclusivamente al gobierno representativo tal y como lo conoce la teoría liberal de la democracia. Para que esta interpretación de la república tenga sentido, lo popular no puede limitarse a ser una dimensión pasiva de la política. $\mathrm{Su}$ actividad ha de articularse con instituciones y liderazgos que no solamente

tada por Gordon S. Wood. Estas dos últimas corrientes instalan una interpretación alternativa de la Revolución de 1776 que pone el énfasis más en las ideas republicanas que en las condiciones económicas o la recepción del liberalismo lockeano. Daniel T. RodGERs, "Republicanism, the Career of a Concept": The Journal of American History, vol. 79, n. ${ }^{\circ} 1$ (1992), pp. 15-21. Sin embargo, la interpretación de Pocock del humanismo cívico, la Inglaterra de los siglos diecisiete y dieciocho y los EE. UU. de los Padres Fundadores responde conceptual y metodológicamente a los planteos de la Escuela de Cambridge. Skinner, a su vez, si bien es un neorrepublicano, no está tan preocupado como Philip Pettit o Pocock por mostrar los elementos no liberales de esta tradición y es menos "idealista" respecto del civismo maquiaveliano. Quentin SKINNER, Liberty before Liberalism, Cambridge University Press, Cambridge, 1999.

${ }^{9}$ Philip Pettit, Republicanism. A Theory of Freedom and Government, Oxford University Press, New York, 2010. El eje de su argumento es que el republicanismo tiene como centro la no dominación (diferente de la no interferencia liberal) y que el autogobierno no es un fin en sí mismo. En su análisis de la actualidad del humanismo cívico, Sintomer por su parte expone claramente las tensiones pero también la autoimplicación de estos dos principios (dominación y autogobierno) en el civismo republicano. Yves Sintomer, "De Leonardo Bruni à Francesco Guicciardini: actualité de l'humanisme civique": Raisons Politiques, n. 26 (2009), p. 16.

${ }^{10}$ Maurizio VIROLI, Repubblicanesimo, Editori Laterza, Bari, 1999.

${ }^{11}$ John P. McCoRMick, "Machiavelli against Republicanism. On the Cambridge School's 'Guicciardinian Moments"': Political Theory, vol. 31, n. ${ }^{\circ} 5$ (2003).

${ }^{12}$ McCormick identifica esta tradición con la concepción madisoniana de la república democrática moderna como forma superadora de la democracia clásica. Desde el punto de vista de este teórico político estadounidense, la concepción madisoniana es heredera del pensamiento republicano renacentista, pero no del "democrático" Machiavelli sino del "aristocrático" Guicciardini. Por eso, no sin ironía sostiene que por sus supuestos valorativos acerca de la república, el libro de Pocock no debiera haberse llamado "The Machiavellian Moment" sino "Guicciardini's Moment". Ibid., p. 616. 
contienen el poder popular y su voluntad innovadora sino que, en determinadas circunstancias, son su condición de posibilidad.

Pero además de las consecuencias de las hermenéuticas neo-republicanas y populistas de Machiavelli en una interpretación elitista o anti-institucional del gobierno popular, hay que contemplar, por otro lado, los sentidos del populismo como concepto. Este último es tan polisémico que incluye desde el "participacionismo" rousseauniano-arendtiano criticado por Pettit en su Republicanism ${ }^{13}$ hasta una caracterización sociológico-discursiva de las experiencias políticas latinoamericanas del siglo veinte al veintiuno ${ }^{14}$, y representa teórica e institucionalmente un problema para la democracia liberal y republicana. Pero este problema no radica, como suele creerse, en el hecho de que liberalismo, por un lado, y populismo, por el otro, tensionen la democracia contemporánea evitando que sea tan políticamente activa o institucionalmente consistente como pudiera ser.

Por paradójico que suene, democracia liberal y democracia populista son menos diferentes de lo que suele creerse y lo que el republicanismo puede ofrecer no es ser el mejor justo medio entre ellas, como parece sostener Pettit ${ }^{15}$, sino mostrar una república en disputa conceptual y política consigo misma. De este conflicto surgirá la audacia teórica para debatir los alcances y límites de las democracias contemporáneas, resignificando no solo las relaciones entre liberalismo y populismo sino también reactualizando la noción de gobierno popular. $\mathrm{Y}$ en eso como en tantas otras cosas, Machiavelli es un exemplum a seguir.

Desde este marco teórico-conceptual, Castruccio Castracani y su vida maquiaveliana resultan un buen punto de partida para explorar la relación entre democracia y liderazgo en clave republicana y las potencialidades de la categoría de gobierno popular como un concepto que evite la Escila del populismo y la Caribdis de la interpretación formalista de las instituciones "republicano-liberales".

Este artículo está estructurado en cuatro partes, además de esta introducción. En la primera se presenta la versión maquiaveliana de la vida de Castracani, su uso político-literario de la crónica histórica. En la segunda sección se discute el sentido político de los exempla maquiavelianos y la ejemplaridad del exemplum de Castracani. En la tercera se analiza qué tipo de virtudes políticas ejemplifica este

${ }^{13}$ Allí Pettit rechaza la identificación de la "república" con la "democracia" en su versión populista, que él identifica extrañamente con la concepción arendtiana de la polis, la soberanía popular rousseauniana o las formas clásicas de democracia directa. PетTiт, Republicanism, pp. 7-11.

${ }^{14}$ Para un análisis de la polisemia conceptual del populismo en los trabajos "científicos" dedicados al fenómeno, se recomienda el texto de Aboy Carlés. Gerardo ABOy CARLÉs, "El populismo entre la ruptura y la integración": Revista Argentina de Ciencia Politica, n. ${ }^{\circ} 15$ (2012).

${ }^{15}$ Pettit, Republicanism, pp. 80-109. 
"príncipe" de la república independiente de Lucca ${ }^{16}$, cuál es su relación con la fortuna y la virtù y de qué modo en este ejemplo se relacionan institución con innovación y poder personal con participación popular. Finalmente, tomando como referencia esta opera de Niccolò Machiavelli muy poco trabajada por la crítica teórico-política, como mencionábamos más arriba, se abre una discusión acerca de las potencialidades teóricas y analíticas de la categoría de gobierno popular para articular democracia y liderazgo sin abandonar la matriz republicana, al menos, la maquiaveliana.

\section{Crónica y Ficción como fuentes de la Teoría Política}

La vida de Castruccio Castracani es un texto tardío en la producción de Machiavelli. Sin embargo, sus temas, sus personajes (Castracani y Florencia, como república militar y políticamente fallida) e incluso algunos de los referentes utilizados para construir la semblanza del "príncipe" o más precisamente del condotiero (Ciro, Filipo, Alejandro, Rómulo, Moisés, Escipión y, más cercanos en el tiempo en que vivió Machiavelli, Cesare Borgia y Pandolfo Petrucci) estaban presentes en su pluma desde hacía casi una década. De hecho, al final de esta nouvelle biográfica, Machiavelli sintetiza (y ficcionaliza, ya que lo hace morir tres años antes de la edad que tenía realmente cuando falleció) la vida de Castracani y da cuenta de por qué se trataba de una vida ejemplar, política y teóricamente hablando:

Vivió cuarenta y cuatro años y se comportó como un príncipe en cualquiera de los lances de la suerte. Y como eran muchos los recuerdos de su buena fortuna también quiso que hubiese algunos de su mala fortuna, por lo que las cadenas que sufrió en prisión todavía se ven colgadas en la torre que era su casa, puestas allí por él para recordatorio de su adversidad. Y porque en vida no fue ni inferior a Filipo de Macedonia, padre de Alejandro, ni a Escipión de Roma, murió a la edad de ambos; y sin duda los habría superados a ambos y en vez de Lucca hubiese tenido como patria a Macedonia o Roma ${ }^{17}$.

${ }^{16}$ Machiavelli afirma que en la Toscana hay tres repúblicas, Florencia, Siena y Lucca, y otras tantas ciudades que aspiraban a recuperar su libertad. Ninguna de las tres dejó de ser considerada una república, que en este caso se usa como sinónimo de gobierno popular, aunque todas ellas estaban lo suficientemente corrompidas como para necesitar de un poder regio para poner freno a la ambición y la corruptela de los poderosos. Todavía no encontró en la Toscana el hombre que pudiera hacerlo, aunque Castracani y Petrucci (vide infra pp. 46 y ss.) estuvieran más cerca del gran hombre providencial que los Medici. Maquiavelo, Discursos sobre la primera década de Tito Livio, p. 170.

${ }^{17}$ Maquiavelo, La vida de Castruccio Castracani, pp. 78-79. El texto original en italiano es el siguiente: "Visse XXXXVII*, e fu in ogni fortuna principe. E come dalla sua buona fortuna ne 
Para comprender el simbolismo de la figura de Castruccio para el pasado y el presente político que Machiavelli interpreta es importante recuperar algo de historia. Una historia que tiene dos sentidos complementarios. La primera refiere al contexto histórico (la Historia con mayúscula, o History) en el cual Machiavelli se decide a escribir este relato y la segunda, a los acontecimientos que él hilvana dentro del relato mismo. Esa es la historia que los angloparlantes llaman story. Considerando esta diferencia, primero nos vamos a detener en el daimon maquiaveliano cuando se decide por narrar la vida de Castracani y luego en cómo su propio relato de los hechos y palabras de Castruccio nos revelan un inesperado daimon que hace de un personaje histórico conocido, pero no demasiado admirado o admirable (según el cronista de que se trate), un exemplum que moderniza en un sentido clásico las vidas ejemplares de Suetonio (70-130 e. c.) y Plutarco (ca. 46-ca. 120 e. c. $)^{18}$.

Para realizar ambos recorridos nos vamos apoyar en diversas obras. Además del propio texto de Machiavelli, nos serviremos de la obra de biógrafos suyos (como Maurizio Viroli); de cronistas de la historia de Castracani como Niccolò Tegrimi (1428-1547) ${ }^{19}$ y Giovanni Villani (ca. 1276-1348) ${ }^{20}$, el primero contemporáneo de Machiavelli y el segundo de Castracani; y de algunos comentaristas que hicieron de este texto objeto de análisis teórico-político o literario como Joseph C. McFarland ${ }^{21}$ y Peter Bondanella ${ }^{22}$.

Niccolò Machiavelli llega a Lucca en julio de 1520 para resolver el caso del mercader de esa ciudad, Michele Guinigi, cuya quiebra había perjudicado a varios mercaderes florentinos. No es ya el segundo secretario de la cancillería

appariscono assai memorie, così volle che ancora della cattiva apparissero; perché le manette con le quali stette incatenato in prigione si veggono ancora oggi fitte nella torre della sua abitazione, dove da lui furono messe acciò facessero sempre fede della sua avversità. E perché vivendo ei non fu inferiore né a Filippo di Macedoni, padre di Alessandro, né a Scipione di Roma, ei mori nella età dell'uno e dell'altro, ei senza dubbio avrebbe superato l'uno e l'altro, se in cambio di Lucca, egli avessi avuto per sua patria Macedonia o Roma". MACHIAVELLI, "La vita di Castruccio Castracani”, p. 301. *En la versión italiana el editor corrige el error de Machiavelli y pone la edad a la que efectivamente murió Castruccio, sin darse cuenta de que afecta el sentido del argumento. Ibidem.

${ }^{18}$ Arendt diferenciaba entre la Historia (History) y la historia o relato (story). En su concepción de la política, la Historia se construía de las historias donde el sujeto revelaba con acciones y discursos su daimon. Hannah ARENDT, The Human Condition, Chicago University Press, Chicago, 1998, p. 205.

${ }^{19}$ Niccolò Tegrimi, Vita Catruccii Antelminelli Castracani Lucensis Ducis, Typografia Societatis Palatine, Milano, 1732.

${ }^{20}$ Giovanni Villani, Nuova Cronica, Ugo Guanda, Parma, 1991.

${ }^{21}$ MACFARLAND, "Machiavelli's Imagination of Excellent Men".

${ }^{22}$ Bondanella, "Castracani: Machiavelli's Archetypal Prince". 
sino un simple ciudadano que cumple un encargo de la Señoría. Allí escribe un Sumario de los asuntos de la Ciudad de Lucca cuyas observaciones reflejan tanto el derrotero de las instituciones políticas de la ciudad como las lecturas y reflexiones que un Machiavelli alejado por obligación de su tarea diplomática había acumulado desde noviembre de 1512, cuando es despedido como funcionario tras la restauración de los Medici. Esa visita fue la excusa para que Machiavelli les regale a sus amigos de los Orti Oricellari (Zanobi Buondelmonti y Luigi Alamanni ${ }^{23}$ ) otro de sus "frutos de ingenio y fantasía":

Más que de una historia o una biografía se trataba de un imaginativo relato de un hombre que desde una humildísima condición logró, gracias a su fuerza y resolución, su virtù, hacer cosas grandísimas y convertirse en príncipe ${ }^{24}$.

La vita di Castruccio Castracani fue un regalo que algunos de esos amigos "humanistas republicanos" supieron apreciar como tal y que otros, como el propio Zanobi Buondelmonti, criticaron por su falta de rigor historiográfico al hacer uso y abuso de dichos inventados puestos en boca de Castruccio ${ }^{25}$. Y precisamente para comprender esta crítica vamos a presentar una semblanza del relato maquiaveliano y las alteraciones que hace a la crónica ${ }^{26}$ histórica para que la vida de este condotiero se acercara más a un exemplum ideal típico que a una narración de costumbres o un tradicional libro de consejos a los príncipes.

Machiavelli comienza el relato de la vida de Castruccio Castracani inventándole un origen desafortunado: de niño abandonado en el pórtico de un clérigo noble que lo adopta junto con su hermana viuda. Este origen ficcional (el verdadero Castruccio era un noble de la familia Antelminelli) es clave para que la fortuna juegue el rol que de ella se espera en la Teoría Política maquiaveliana: ele-

${ }^{23}$ Buondelmonti (1491-1527) y Alamanni (1495-1556) participaron de una conspiración para asesinar a Giulio de' Medici (1478-1534) en 1522 y fueron desterrados de Florencia.

${ }^{24}$ Maurizio Viroli, La sonrisa de Maquiavelo, Tusquets, Barcelona, 2002, p. 234. La versión original en italiano versa: "Più che una storia e una biografia, è il ritratto immaginato di un uomo che da umilissima condizione riuscì grazie alla sua virtù a fare 'cosse grandissime' e diventare principe”. Maurizio VIrol, Il sorriso di Niccolò. Storia di Machiavelli, Laterza, Roma, 2000, p. 194.

${ }^{25}$ Skinner afirma en coincidencia con Buondelmonti que los epigramas, tomados de Las vidas de filósofos ilustres de Diógenes Laercio, están insertados allí para obtener un efecto retórico y señala también que sus contemporáneos vieron en ella el esbozo de un ensayo de más largo alcance (¿la Historia de Florencia?) y no dedica a La vida de Castruccio Castracani mayores comentarios. Quentin SkINNER, El nacimiento del Estado, Gorla, Buenos Aires, 2003, p. 101.

${ }^{26}$ Sobre la crónica como género historiográfico del Medioevo y principios del Renacimiento véase Hayden White, El contenido de la forma, Paidós, Barcelona, 1992. 
gir a los desafortunados para hacerlos subir al tope de la rueda de la vida. Como Moisés, Rómulo o Ciro (en la versión de Jenofonte, incluso, aunque superficialmente parezca que Machiavelli prefiera la de Tito Livio $^{27}$ ) el Castracani de Machiavelli es un niño abandonado. Invirtiendo el caso de Cesare Borgia (14751507) que empezó su vida política con fortuna, ejército y virtudes prestadas, Castruccio avanza en el cursus honorum de la jefatura político-militar por propio mérito. A pesar de los intentos de su padre Antonio de educarlo para el oficio religioso, el ingenioso niño se revela más interesado por los ejercicios militares y es "adoptado" por Francesco Guinigi, un condotiero inventado y a cuyo hijo biológico, Pagolo, otra invención de Machiavelli, el Castruccio de Niccolò va a transformar en su heredero político. Lo interesante, independientemente del hecho de que el Castruccio real tuviera hijos biológicos en quienes delegar el $\operatorname{poder}^{28}$, es que esta familia adoptiva inventada, que tiene por apellido el del comerciante de Lucca cuya quiebra había afectado a los florentinos y motiva el viaje de Machiavelli a esta ciudad, educa al futuro líder de la misma manera que los cónsules republicanos, primero, y emperadores romanos, después, lo hacían con su prole.

Esta anécdota sirve para dar cuenta del motivo por el cual la elección del sucesor a través o por la vía de la adopción es una forma de transferencia del carisma del poder personal mejor que la hereditaria ${ }^{29}$. A partir de allí, la vida de Castruccio se cruza con las hazañas militares y es entonces cuando las crónicas de la época (escritas casi contemporáneamente a la vida del Castruccio real o a la vida de Machiavelli) aparecen si no como fuente, sí como referencia histórica que es alterada en pos del objetivo de la narración. Este objetivo es ofrecer un tipo ideal de príncipe nuevo que combine la capacidad militar con la astucia y sepa, aunque al final de su vida sienta haber fallado, cuánto pesa la fortuna en los asuntos humanos para dominarla virtuosamente.

En la narración de Machiavelli, tras una campaña con su mentor en la ficción, Castruccio empieza a crecer como figura política en Lucca pero la envidia de ciertos sectores de la ciudad, especialmente la fracción güelfa, le hacen pedir ayuda

${ }^{27}$ Sobre las relaciones de Machiavelli con Jenofonte, en especial en lo que respecta a las vidas y virtudes de los príncipes, véase W. R. Newell, "Machiavelli and Xenophon on Princely Rule: A Double-Edged Encounter": Journal of Politics, vol. 50, n. ${ }^{\circ}$ (1988).

${ }^{28}$ Efectivamente lo hace con su hijo Geri Castracani, MACFARLAND, "Machiavelli's Imagination of Excellent Men", p. 139. Lo que es real es que no se casó, así que sus dichos contrarios al matrimonio (para qué casarse con una mujer si se puede estar con ella sin hacerlo) no serían tan inverosímiles.

${ }^{29}$ Maquiavelo, La vida de Castruccio Castracani, pp. 23-32; Machiavelli, "La vita di Castruccio Castracani”, pp. 276-280. 
de Uguccione della Faggiuola d'Arezzo (1250-1319), señor de Pisa, para proteger la ciudad. Los eventos que aquí se narran coinciden en el lapso temporal (1313-1316) con el orden de la crónica de Villani (1313-1328) ${ }^{30}$, aunque Machiavelli se permite ciertas libertades. En la narración de Machiavelli se le adjudica a un joven y audaz Castruccio el triunfo de Montecatini ${ }^{31}$, que la crónica de Villani refiere como una batalla ganada por Uguccione, y se omite que ya entonces, tras la "reconquista de Lucca", Castracani había firmado un armisticio con Florencia (1317-1320). Tampoco menciona il Machia que Castruccio decide fortificar Lucca, aunque lo cuenta después, luego de la más importante alteración en el relato histórico de Machiavelli, la invención de la conspiración de los Poggio ${ }^{32}$. Machiavelli sigue pensando como en El Príncipe y los Discursos sobre la primera década de Tito Livio (1531) que las fortificaciones, incluso las aparentemente inexpugnables como las de Forlì, de poco sirven ante un atacante audaz y más si se ha hecho del favor del pueblo invadido. Pero acepta que era un lugar común para la protección de las ciudades italianas de la época y deja que su Castracani obre en consecuencia.

Lo más notable aquí es cómo Machiavelli toma de modelo para describir los triunfos del condotiero las batallas que habían protagonizado los estrategas romanos, más que las que efectivamente Castracani llevó a cabo en ese período de su vida. En cierto sentido sus estrategias militares pueden parecer anticuadas, como en los Discorsi y El arte de la guerra $(1521)^{33}$; sin embargo, su comprensión del liderazgo político no lo es. Por ello, tanto o más importante que sus habilidades para planear batallas y motivar a sus fuerzas (algo que pocas veces les resultaba a los capitanes florentinos, nativos o mercenarios) es su potencial de líder popular. El error de Castruccio le hace caer en una trampa de Uguccione y su hijo y es encarcelado por ellos. La acclamatio del pueblo de Lucca en su favor termina con su liberación y su transformación en el príncipe de esta república; un estatus - el de república- que Lucca no perdió ni antes ni después de la muerte de Castracani ${ }^{34}$.

${ }^{30}$ VILLANI, Nuova Cronica, p. 60. Tras la muerte de Villani la crónica fue continuada por su hermano y su sobrino.

${ }^{31}$ Maquiavelo, La vida de Castruccio Castracani, p. 34.

${ }^{32}$ Ibid., p. 45.

${ }^{33}$ Niccolò Machiaveldi, "The Art of War", en Machiavelli: The Chief Works and Others, vol. III, trans. by Allan Gilbert, Duke University Press, Durham, 1989.

${ }^{34}$ Ibid., p. 42; MachiavelLI, "La vita de Castruccio Castracani”, p. 284. 
Así pues, en esta primera etapa más que alterar la crónica en su cronología, se reinterpreta y se reescriben los hechos sirviéndose tanto de la experiencia de las cosas modernas como de lo aprendido en la repetida lectura de las antiguas ${ }^{35}$. Los cambios más radicales en el tiempo del relato en relación con el tiempo de la historia se dan a partir del primer contacto de Castracani con el emperador Federico, hecho que en realidad no sucedió, ya que a quien conoce el Castruccio histórico es a Luis de Baviera (1282-1347) a instancias del cual es designado vicario y senador en Roma. Machiavelli deja el episodio romano para el segundo encuentro con el emperador (que nunca sucedió) y apenas menciona ocasionalmente las primeras amenazas a Florencia y omite la toma de Pistoia (sucedidas entre 1323 y 1325) para centrarse en una conspiración que no fue real, la de la familia Poggio. Allí Machiavelli presenta una nueva versión de uno de los episodios más dramáticamente logrados de El Príncipe, la eliminación de los Orsini y los Colonna y el ajusticiamiento de Ramiro de Orco (1452-1502), con los que Cesare Borgia se garantizó el dominio de la Romaña. En ambos casos se afirma como en los Discursos ${ }^{36}$ que las conspiraciones, sean de pocos por falta de apoyo, sean de muchos por extendidas, son riesgosas o bien por la virtud de los ordine republicanos o bien por la audacia y la astucia de quienes gobiernan los principados.

Cabe decir que, si bien Machiavelli introduce el relato de un hecho inexistente para fortalecer el vínculo de este exemplum todavía medieval con un príncipe nuevo del Renacimiento (el duque Valentino), el Castruccio histórico fue objeto de una conspiración por parte de los Quartegiani y Carlos de Calabria (1298-1328) que logra desmantelar. Pero más aún, tras mostrar cuán prudente fue Castruccio para evitar ser víctima de conjurados, Machiavelli revela cómo hizo uso del método de generar conspiraciones o, mejor dicho, divisiones en las ciudades para tomarlas. Su estrategia consistió en hacer creer a un grupo que él los apoyaba y a otro, que contaban con el apoyo de Pagolo, para unirse ambos luego y lograr así terminar con las dos facciones. Por consiguiente, aunque utiliza la ficción al introducir un personaje no histórico como Pagolo Guinigi, lo que hizo el Castruccio maquiaveliano para tomar Pistoia era coherente con los hábitos del condotiero histórico en cuestión ${ }^{37}$.

${ }^{35}$ Maquiavelo, El Príncipe, p. 33.

${ }^{36}$ En los ejemplos se refiere a la conjura de los Pazzi pero también a cómo Pandolfo de Siena descubre una conjura en su contra. En síntesis, en las repúblicas o principados, si los líderes políticos que conducen lo stato son sagaces, las conjuras resultan inútiles. Maquiavelo, Discursos sobre la primera década de Tito Livio, pp. 320-327.

${ }^{37}$ Maquiavelo, La vida de Castruccio Castracani, pp. 39-40; Machiavelli, "La vita de Castruccio Castracani”, pp. 287-288. 
Lo que hace entonces Machiavelli, ya sea para dar mayor tono dramático al relato, ya sea para dejar más en evidencia la impericia militar y diplomática de las autoridades florentinas, es narrar casi una tras otra las victorias de Castruccio sobre Florencia. La victoria de Serravalle es sucedida por la recuperación de Pistoia (que históricamente la precede), el reordenamiento de los florentinos, su rendición al duque de Calabria, llegando finalmente al clímax con el triunfo de Castruccio en Fucecchio ante las tropas florentinas ya subordinadas al hijo del rey de Nápoles.

La funcionalidad de esta secuencia narrativa es dar cuenta del arte de la guerra que Machiavelli consideraba más efectivo (uso de la infantería, aplicación selectiva de la caballería, elección coyuntural entre la defensa y el ataque) pero también dar una lección de política. Castruccio muere antes de estabilizar el stato de Lucca. Cuando la estrella de su fortuna se apaga, él pierde la vida — como todo héroe trágico que se precie - en un evento fortuito que demuestra que por virtuoso que uno sea la ambición excesiva (hybris) es castigada, y que todo lo que se haga por evitar el final no hace sino desencadenarlo. Sin embargo, a diferencia de Cesare Borgia, él sí sabe lo que le está pasando gracias a la educación maquiaveliana de los príncipes. Y al saberlo, aun sin haberlo evitado, deja un extraño legado: los derrotados por la fortuna pueden revertir su historia, si al escribir la Historia se nos permite algo más que la cronología.

Este relato culmina con la muerte de Castruccio sucedida por un epílogo de dichos más dignos de un filósofo socrático que de un condotiero sanguinario ${ }^{38}$. Tras leerlo, surgen al menos dos interrogantes: ¿puede un príncipe afortunadamente desafortunado ser un ejemplo político? Y por otra parte, teniendo en cuenta el fracaso del Castruccio ficcional, al no dejar un stato tan estable como ampliado, y considerando las consecuencias de las campañas y la acción política del Castruccio histórico, que no fundó ninguna institucionalidad nueva en Lucca ni ofreció nuevas herramientas para su preservación, ¿se pone en evidencia que el príncipe nuevo maquiaveliano es un personaje conceptual ${ }^{39}$ y políticamente fallido? ${ }^{40}$. No lo creemos así, porque en tal caso sería gratuita "la astucia imaginativa" de Machiavelli ${ }^{41}$. Justamente para abordar ese punto retomaremos la

${ }^{38}$ Leo Strauss, Thoughts on Machiavelli, Midway, Chicago, 1984, p. 224.

${ }^{39}$ Definimos al personaje conceptual siguiendo a Gilles Deleuze (1925-1995) y Félix Guattari (1930-1992): "La diferencia entre los personajes conceptuales y las figuras estéticas consiste, en primer lugar, en lo siguiente: unos son potencias de conceptos y otros potencias de afectos o preceptos...El personaje conceptual es el devenir o el sujeto de la filosofía que asume el valor del filósofo". Gilles Deleuze y Felix GuatTari, ¿Qué es la Filosofia?, Anagrama, Barcelona, 1993, pp. 66-67.

${ }^{40}$ Macfarland, "Machiavelli's Imagination of Excellent Men”, p. 144.

${ }^{41}$ Ibid., p. 145. 
cuestión de los exempla como parte de un género literario y una estrategia político conceptual.

Para cerrar este apartado podríamos recuperar la distinción arendtiana entre Historia e historia antes mencionadas. Se puede concluir que la adaptación ficcional de la crónica hecha por Machiavelli revela un Castruccio cuyo daimon no se limita a un sagaz líder militar o a un personaje colorido de la baja Edad Media "italiana" sino en la encarnación personal de un modo de concebir la política. Se trata claramente de un exemplum de un tipo de político y de un momento conceptual maquiaveliano.

Pero esa historia es escrita dentro de una Historia que Machiavelli construye a la vez que relata, y ella misma tiene un daimon propio que se revela de manera sorprendente. Por ello, resulta sintomático que su encuentro con la historia de Lucca y su príncipe se produzca gracias a su labor diplomática. Para Machiavelli su Teoría Política era tan partícipe de su actividad como "funcionario" de su stato o mandatario de un príncipe como lo eran sus lecturas de los clásicos antiguos. Entonces podríamos preguntarnos, aun a riesgo de causar el encono de Leo Strauss (1899-1973) ${ }^{42}$, si Machiavelli no es a su modo un ejemplo de un sabio que deviene en funcionario por pasión y no como consecuencia de la escatología histórica de la modernidad judeo-cristiana y hegeliana ${ }^{43}$; y si en ese devenir acaso no solo contribuye a democratizar los secretos de la política clásica sino que además funda una praxis política vital y lúcidamente teórica.

\section{EL SENTIDO POLÍTICO DE LOS EXEMPLA}

La vida de Castruccio Castracani es consecuencia de una misión casi diplomática a Lucca a pedido de Giulio de' Medici (1478-1534), futuro papa Clemente VII, quien al regreso le encargará a Machiavelli una versión de la historia de su ciudad natal. Por ese motivo, y por el hecho de que La vida de Castruccio Cas-

${ }^{42}$ Strauss, Thoughts on Machiavelli, p. 225.

${ }^{43}$ No puede decirse que el modelo de sabio funcionario maquiaveliano sea idéntico al de Kojève pero vale la pena recordar sus reflexiones al respecto, unas consideraciones que fueron parte de su polémica con Strauss. "Adoro este trabajo. Para el intelectual, el éxito ocupa el lugar del logro. Si se escribe un libro, se obtiene éxito, es todo. Aquí es diferente [con aquí se refiere a su trabajo diplomático], porque hay logros. Le he dicho el placer que sentí cuando mi sistema aduanero fue aceptado. Es como una forma superior de juego. Se viaja, se pertenece a una elite internacional, que ha reemplazado a la aristocracia, y se conocen personas que no son novatos". Alexandre KoJĖve, "Los filósofos no me interesan, busco a los sabios", en El emperador Juliano y su arte de escribir, Grama, Buenos Aires, 2003, p. 56. 
tracani y la Historia de Florencia ${ }^{44}$ fueron escritas casi contemporáneamente, se las suele comparar como dos relatos de príncipes. Ciertamente puede decirse que Castruccio Castracani en un caso, Cosme de Medici (1389-1464) en el otro ${ }^{45}$, operan como figuras contrastantes. Pero aunque Machiavelli no lo diga, Castruccio y Cosme tenían algo en común: ambos se apoyaban en el pueblo, aunque el partido del Medici fuera más plebeyo que popular. Lo malo en el caso de Cosme es que la derrota de los grandes tenga por consecuencia la sujeción definitiva de Florencia a la autoridad papal como antes, en los tiempos de Castracani, lo había estado al reino de Nápoles. Por cristiano, esteta, magnánimo y poco belicoso Cosme no puede, a juicio de Machiavelli, refundar el ordine republicano florentino y mucho menos constituir un tipo ideal de príncipe que revele la originalidad del momento conceptual maquiaveliano de la república y de la Teoría Política. Por eso, Machiavelli, y nosotros con él, vamos a recurrir a otros príncipes renacentistas que tienen mucho más que ver con el exemplum de Castruccio Castracani que el "favorito" de Machiavelli, Cesare Borgia.

En El Príncipe no hay ninguna mención al condotiero de Lucca pero sí hay dos importantes referencias a otro gobernante que no es el hijo del papa Alejandro IV y que resulta, al final, mucho más exitoso que él en lo que la conservación de lo stato se refiere: Pandolfo Petrucci (1452-1512). Catalogado en algunas biografías como tirano, epíteto también aplicado a Castruccio ${ }^{46}$, el príncipe

${ }^{44}$ Nicolás Maquiavelo, Historia de Florencia, Alfaguara, Madrid, 1979. Cabe recordar que Francesco Guicciardini (1483-1540) escribe una versión de la historia de la ciudad de Florencia bastante diferente a la de Machiavelli. En ella prima no solo la visión desde arriba (es decir, el punto de vista de un aristócrata con poder) sino también se presenta un relato anecdótico de costumbres donde los ejemplos no funcionan como exempla ideal-típicos sino como un estilo narrativo orientado a generar efecto de realidad. A pesar de esto, McCormick sostiene que por su apuesta a favor de la moderación política de cierta aristocracia como forma de alcanzar la estabilidad institucional, Istorie Fiorentini (1525) es el menos democrático de los textos de Machiavelli. McCormick, "Machiavelli Against Republicanism", p. 632. Guicciardini muere en 1540, trece años después que Machiavelli. Su Historia de Florencia se edita postmortem en 1576, y salvo las rediciones de 1578, 1582 y 1583, no se reedita hasta el siglo diecinueve. Francesco GuICCIARDINI, Historia de Florencia, 1378-1509, FCE, México, 2006.

${ }^{45}$ Maquiavelo, Historia de Florencia, pp. 238-252.

${ }^{46}$ Queda para futuros trabajos el análisis del concepto antiguo de tiranía y la manera en que el mismo es apropiado en el Renacimiento. Vale mencionar a título ilustrativo que la tragedia Edipo Rey se denomina originalmente Edipo, Tirano, debido no tanto al modo en que Edipo ejercía su autoridad en Tebas sino a su legitimidad de origen: siendo el hijo del rey, al no saberlo, llega al poder como príncipe nuevo y se apoya en su ingenio al develar el enigma de la esfinge. En los Discorsi Machiavelli se refiere a la tiranía como forma desviada de la política regia pero no hace referencia ni a Pandolfo ni a Castruccio. Maquiavelo, Discursos sobre la primera década de Tito Livio, p. 180. 
de Siena es conocido por Machiavelli en 1503, en ocasión de una larga entrevista que tiene con el duque Valentino al que había visto por vez primera dos años antes. Pandolfo es entre los exempla modernos, es decir, contemporáneos a Machiavelli, el más parecido a Castruccio: entiende que la fortuna es variable y que el buen príncipe debe saber aceptar sus vaivenes. Y, por ende, ambos comprenderían bien la siguiente sentencia del autor de El principe, aunque no llegaran a suscribirla: "Concluyo pues, que puesto que la suerte cambia y los hombres se obstinan en sus actitudes tienen éxito mientras se muestran acordes, $\mathrm{y}$ fracasan cuando son discordes" ${ }^{\prime 47}$.

Por ello, Petrucci gobernó su ciudad sirviéndose de quienes en principio se mostraron como sus enemigos y que necesitaban de su apoyo para mantener su condición $^{48}$. Hay otro rasgo de Pandolfo, la capacidad de elegir buenos consejeros (testimoniada en su elección de Antonio da Venafro [1459-1530] como ministro) ${ }^{49}$, que no queda tan claro que Castracani compartiese. En el relato de Machiavelli, Castracani parece decidir siempre solo; si bien, por otra parte, considerando la sagacidad de sus dichos finales ${ }^{50}$ y su sentido de la autocrítica es probable que su biógrafo también le adjudicase dicha capacidad ${ }^{51}$.

En los Discorsi aparecen dos referencias a Castruccio. La primera se repite en el Libro II de la Historia de Florencia y relata cómo Castracani vence en 1325 a los florentinos que debieron aceptar el vasallaje del rey de Nápoles, Roberto (1278-1343), para que los defendiera del asolamiento del condotiero a tierras toscanas — una defensa que resultó infructuosa ${ }^{52}$. La otra referencia amplía la

${ }^{47}$ Maquiavelo, El Príncipe, p. 158. La versión original italiana de la presente cita es: "Concludo, adunque, che variando la fortuna, e stando li uomini ne' loro modi ostinati, sono felice mentre concordano insieme, come discordano, infelice". Machiavelli, Il Principe, p. 132.

${ }^{48}$ Maquiavelo, Discursos sobre la primera década de Tito Livio, pp. 137-138.

${ }^{49}$ En el capítulo XXII de El Príncipe, se sostiene que hay tres tipos de inteligencia: la que distingue por sí misma, la que distingue lo que otro comprende (una excelentísima y otra excelente) y la que no comprende ni por sí misma ni por otros (inútil). Castracani tendría las dos primeras, Pandolfo al menos la segunda, y el emperador Maximiliano de Austria sería un ejemplo de la tercera por su impericia para gobernar y por ser tan influenciable por cualquiera que lo aconsejara que era incapaz de decidir. Maquiavelo, El Príncipe, pp. 147, 150.

${ }^{50}$ Vide infra pp. 19-20.

${ }^{51}$ Aunque Machiavelli tampoco realice una comparación explícita sería interesante confrontar los casos de Castracani, Petrucci y Pier Soderini. En el último caso se trata del jefe político de una república que, aun con limitaciones institucionales y personales, estuvo bastante cerca del modelo del gobierno popular y cuando no lo estuvo, la existencia de procedimientos como la acusación, propios de la república romana, podrían haber salvado lo stato republicano popular evitando la restauración de los Medici. John P. McCormick, "Machiavelli's Political Trials and The Free Way of Life": Political Theory, vol. 35, n. ${ }^{\circ} 4$ (2007).

${ }_{52}$ Maquiavelo, Discursos sobre la primera década de Tito Livio, p. 219; MaQuiavelo, La vida de Castruccio Castracani, pp. 58-59; MACHIAVELli, "La vita di Castruccio Castracani”, pp. 292-293. 
cuestión para demostrar cómo los ciudadanos de Florencia, valientes en las guerras lejanas, no lo eran cuando atacaban su territorio. De allí deriva Machiavelli un consejo general, que quien tenga bien organizado su pueblo le conviene esperar la guerra en su territorio mientras que, si se encuentra en la situación contraria, debe preferir combatir fuera de él. Una enseñanza que Castruccio aplica en la toma del Castillo Serravalle para organizar la defensa contra los florentinos como si fuese el desfiladero de las Termópilas. Todas estas menciones son complementarias a lo que Machiavelli había escrito en El arte de la guerra y se encuentran también en el libro II de los Discorsi, dedicado casi por entero al debate acerca de cuál es la mejor organización militar para que una república pueda ser estable internamente y expansiva en su política exterior, o cuando menos no fallidamente defensiva como Florencia. Y reaparecen en la Vida de Castruccio que aparenta hacer todo bien como capitán militar mientras que los florentinos lo hacen todo mal.

En este punto vale la pena detenerse en el sentido de los exempla maquiavelianos y, en especial, en el exemplum de Castracani. Al tratarlo, Machiavelli se sirve de un rasgo característico de la historiografía humanista que tiene importantes precedentes clásicos y medievales. Machiavelli encuentra en Castruccio un arquetipo que encarna los conceptos y observaciones analíticas centrales de su Teoría Política. Contrariamente a lo que sostiene uno de los analistas más reconocidos de la obra de Machiavelli en el mundo anglosajón, el italianista John Humphreys Whitfield (1906-1995) ${ }^{53}$, la vida de Castruccio Castracani no es un texto menor que nada aporta a la concepción maquiaveliana de la política. $\mathrm{Ni}$ tampoco como cree Macfarland ${ }^{54}$ un fallido contrapunto de un príncipe casi nada ejemplar como Cosme el viejo. Castruccio es, como afirma Bondanella ${ }^{55}$, un arquetipo.

Desde el punto de vista narrativo, se trata de un arquetipo porque como ya se pudo observar al considerar la ficcionalización maquiaveliana de la crónica, su biografía comparte algunos rasgos del ideal típico de los exempla tan característicos de la Edad Media tardía y el Renacimiento: el personaje tiene un origen bajo u oscuro, vive un rito de pasaje a la adultez donde se muestran sus cualidades y, tras el apogeo, llega el final y cierta forma póstuma de redención.

${ }^{53}$ John Humphreys WhitfiEld, "Machiavelli and Castruccio", en Discourses on Machiavelli, W. Heffer \& Sons, Cambridge, 1969, passim.

${ }^{54}$ Macfarland, "Machiavelli's Imagination of Excellent Men”, pp. 138-145.

${ }^{55}$ Bondanella, "Castracani: Machiavelli’s Archetypal Prince”, p. 310. 
Pero Machiavelli también le suma otros rasgos que permiten contrastar a este condotiero con otros exempla principescos empleados por él mismo en otros momentos de su obra. Con Castruccio, Machiavelli cierra un ciclo de relatos de vidas de políticos, asumiendo ahora con toda radicalidad el impacto de la fortuna en los asuntos humanos e innovando conceptualmente el sentido de la prudencia política. Puesto en palabras de Bondanella:

Tomando prestada la estructura arquetípica de la vida heroica de la literatura y la leyenda, Machiavelli es capaz de hacer de su biografía de Castruccio Castracani una obra artística, una obra que seguramente presenta una estética que satisface la representación perfecta del héroe dentro del marco maquiaveliano de ideas políticas ${ }^{56}$.

Este arquetipo no solo sintetiza los atributos esperables de un buen líder sino también con una Oración Fúnebre, como Tucídides (ca. 460-ca. 395 a. e. c. $)^{57}$, se expresa en boca de Castracani el legado político maquiaveliano:

Si hubiese creído, hijo mío, que la fortuna trocaría en medio del camino a la gloria que tantos sucesos felices me prometían, me habría fatigado menos y te habría dejado un estado menor, menos enemigos, menos envidia...No debes poner esperanzas en nada que no sea tu esfuerzo y el recuerdo de mi virtud y la reputación que esta victoria te deja, la que te ayudará, si sabés usarla con prudencia, lograr un fácil acuerdo con los florentinos y desconcertarlos con la derrota ${ }^{58}$.

En síntesis, el príncipe nuevo maquiaveliano forma parte de un momento conceptual donde fortuna y virtud, tantas veces en contradicción, se transforman a instancias de la virtù, en antinomias convergentes. Pero también el personaje

56 "In borrowing the archetypal structure of the heroic life from literature and legend, Machiavelli was able to make his biography of Castruccio Castracani a work of art, a work which surely presented an esthetically satisfying picture of the perfect hero within the Machiavellian framework of political ideas". Ibid., pp. 312-313.

${ }^{57}$ Sobre las relaciones de Machiavelli con Tucídides se puede consultar el texto de Pires. En él, no solo refuta a quienes como Bondanella afirman que casi no existe relación entre estos autores sino también a quienes plantean que la concepción de la virtud en ambos es contrapuesta. Pires sostiene que Tucídides y Machiavelli comparten tanto el cariz democrático como el rol de la persuasión en la política, una concepción topográfica del poder y una interpretación realista de la historia. Francisco Murari Pires, "Machiavel, la cour des Antiques et (le dialogue) avec Thucydide": Dialogues d'histoire ancienne, vol. 34, n. ${ }^{\circ} 1$ (2008), p. 81; Peter Bondanella, Machiavelli and the Art of Renaissance History, Wayne State University Press, Detroit, 1973, p. 17.

${ }^{58}$ Maquiavelo, La vida de Castruccio Castracani, pp. 68-69. Subrayado en el original. Para la versión en italiano, véase MACHIAVELLI, "La vita de Castruccio Castracani”, pp. 295- 297. 
conceptual del príncipe nuevo revela la necesidad de cambio que necesita todo orden político (entonces lo stato), especialmente republicano, para su preservación. Si la virtud política no se democratiza (es decir, si la virtud de uno no se convierte en virtud de muchos) y el carisma personal no se transforma en ley (en el sentido de institución históricamente legitimada y no formalista o instrumental), la herencia de los afortunados no es otra que la decadencia.

Por esta ambivalencia que la hace necesaria y afortunada, pero también desafortunada, y cuando es desvirtuada, peligrosa, el príncipe maquiaveliano es una figura del poder personal que sin ser antirrepublicana, ni mucho menos apolítica, necesita de algo más para que la política y sus ordini puedan renovarse y sobrevivir: que el apoyo popular se transforme en poder popular.

\section{FORTUNA, VIRTÙ Y VIRTUDES DE UN CONDOTIERO}

Este apartado tiene por objeto el análisis de aquellos conceptos clave de los cuales Machiavelli se ha servido para construir la figura ficcional de Castruccio Castracani. La mejor síntesis de este exemplum y del testamento político de su biógrafo se encuentra en la oración fúnebre cuyo fragmento más destacado se citó en el apartado anterior. Los conceptos que allí se ponen en juego forman parte del legado maquiaveliano a la Teoría Política moderna, clásica y contemporánea, y han sido abordados con atención por los intérpretes más reconocidos de su obra política. Sin embargo, pocos se han detenido en La vida de Castruccio Castracani como un momento conceptual del momento maquiaveliano de la teoría política republicana.

Para analizar cómo operan algunos conceptos clave del pensamiento político de Machiavelli en este caso, nos centraremos en los enfoques de dos historiadores del pensamiento político que con sus textos no solamente modificaron orientaciones de sus historiografías locales ${ }^{59}$, sino también revalorizaron los conceptos en la Teoría y el análisis político. Uno de ellos es Quentin Skinner. Como mencionábamos más arriba, su visión es un paradigma de la Historia Intelectual en la línea de la Escuela de Cambridge, que tiene por principal objeto el estudio de las ideas políticas en su contexto de producción específico para interpretar desde allí la intención del autor en cuestión. El otro es Pocock. Este historiador estadounidense instaló, junto a Pierre Rosanvallon, la noción de momento en el horizonte de sentido de la Historia Conceptual y la Teoría Política. Para ambos el momento no es solamente una bella metáfora sino una herramienta heurística.

\footnotetext{
${ }^{59}$ RodGERS, "Republicanism, the Career of a Concept", passim.
} 
Si en algo coinciden Skinner y Pocock, a pesar de sus diferencias respecto al peso de la tradición aristotélica en Machiavelli y la influencia de los Studiae Humanitatis, donde uno prioriza a los juristas y el otro a los literatos (más retóricos que rhetores $\left.{ }^{60}\right)$, es en la conceptualización de la fortuna y la importancia de virtù en la obra de Machiavelli.

Otra extraña coincidencia es que para ejemplificar el uso de la virtù y de otros conceptos (virtudes en plural, stato, conflicto, ordine) o figuras (príncipe, legislador, fundador) ninguno se refiere a La vida de Castruccio Castracani.

Respecto de la fortuna ambos autores resaltan hasta qué punto los humanistas, y dentro de ellos Machiavelli, recuperan y resignifican la tradición antigua. Los humanistas abandonan, o al menos matizan, tanto la visión cristianizada de Anicio Manlio Torcuato Severino Boecio (484-524), donde la fortuna era sinónimo de la providencia, como la concepción de quienes creían, en la Edad Media, que la fortuna era una mitologización de la que se servían aquellos que pensaban que la historia era caótica y rechazaban su dimensión escatológica ${ }^{61}$. La virtù maquiaveliana es entre otras cosas el sentido de la oportunidad de la que se sirve el hombre político para seducir a esta voluble mujer que como toda mujer que se precie de tal —al menos para el renacentista Machiavelli- se deja ser amada con más placer por los jóvenes y audaces. $\mathrm{O}$ para decirlo en términos de Louis Althusser (1918-1990) ${ }^{62}$, mientras la virtù es la figura de la conciencia, la fortuna es la espontaneidad insondable, imprevisible y negativa ${ }^{63}$. Pero ese vir que sabe atraer a su favor, al menos temporalmente, los vaivenes de la fortuna, no es el hombre ni el ciudadano clásicamente virtuoso. Tiene otras virtudes y

${ }^{60}$ El rhetor es una figura jurídico política que suele ser tomada como sinónimo del teórico político. Ver Gabriela Rodríguez y Pamela Morales, "Teología y Política: ¿oposición o antinomia convergente? Actualidad de la polémica entre un Jurista rhetor y un teólogo apolítico", en Óscar Mauricio Donato (comp.), Entre Antiguos y Modernos, Hermenéutica, Ética y Política, Universidad Libre, Bogotá, 2010, p. 139.

${ }^{61}$ Quentin SkInNER, Maquiavelo, Alianza Editorial, Madrid, 1998, pp. 37-38; Pocock, El momento maquiavélico, p. 246.

${ }^{62}$ Louis Althusser, Politica e Historia. De Maquiavelo a Marx, Katz, Madrid, 2007, p. 221.

${ }^{63}$ En su lección sobre Machiavelli el filósofo francés añade que la virtù en Machiavelli tiene un problema conceptual estructural: se define por sus efectos y eso puede conducir a que al fin y al cabo la virtud (que tiene por objeto transformar lo contingente en necesario) termine siendo un epifenómeno de la fortuna. La crítica es interesante y válida pero, por un lado, presupone una noción de necesidad histórica que Machiavelli no siempre parece compartir (como dice el propio Althusser no hay en Machiavelli una filosofía de la historia en sentido estrictamente moderno) y, por el otro, parte de una concepción deductiva de los conceptos teóricos y no reconoce que ellos pueden construirse a partir de ejemplos históricos en el marco de una metodología ideal típica o arquetípica. Ibid., p. 223. 
tiene fundamentalmente otra virtù, mantener o conservar lo stato; aunque muchas veces para hacerlo deba expandirlo y termine condenado por su propia hybris como Castruccio, o como le ocurre a los romanos por la dificultades intrínsecas de la forma política imperial que, a diferencia de Dante, el para nada güelfo Machiavelli estaba lejos de admirar ${ }^{64}$.

Mientras Skinner y Pocock coinciden en el análisis de la virtù y la fortuna, en las virtudes hay una clara diferencia en estos dos intérpretes de Machiavelli y su momento. Para Skinner ${ }^{65}$ de las virtudes clásicas —o más precisamente estoicas, porque se las debemos a Cicerón y Séneca-, Machiavelli deja de lado o invierte básicamente tres: la liberalidad, la magnanimidad y la honestidad.

Aunque no pareciera particularmente avaro en sus acciones y sus dichos, ninguno de ellos testimonia que Castruccio haya sido particularmente generoso con su dinero o con el de las arcas públicas. Incluso se atreve a criticar a quienes tienen casas grandes o comen de más ${ }^{66}$. Podría decirse que en términos arquitectónicos estaba más interesado en dar un ejemplo político (recordemos que dejó en su casa la cadenas donde estuvo prisionero para acordarse de un momento en el que le fue adversa la fortuna), que en embellecer su ciudad.

Respecto de la honestidad, era sagaz generando divisiones en las ciudades que quería conquistar y hábil en desbaratar conspiraciones, pero Castruccio no estaba demasiado con mantener la palabra empeñada, si esto no era necesario ${ }^{67}$. Tampoco se muestra por demás piadoso, ya que no solo es parte de la facción gibelina que apoyaba al emperador, sino que con un dejo neorromano que Machiavelli inventa o subraya, su amor a la patria precede a su fe en la iglesia universal. Y finalmente, durante la conspiración de los Poggio, Castracani muestra à la Borgia cómo no es adecuado ser magnánimo cuando se quiere dar una lección a los enemigos actuales y advertir a los por venir ${ }^{68}$. Esta creencia se refuerza en sus propias palabras cuando frente a la pregunta de por qué había

${ }^{64}$ Sobre la relación teórica entre Machiavelli y Dante, véase Larry I. PETERMAn, "Machiavelli's Dante \& the Sources of Machiavellianism": Polity, vol. 20, n. ${ }^{\circ} 2$ (1987). Los güelfos eran en las guerras religiosas de los siglos doce, trece y catorce los partidarios del Papa y los gibelinos, los del emperador germánico.

${ }^{65}$ SKInNER, Maquiavelo, pp. 50-56.

${ }^{66}$ Maquiavelo, La vida de Castruccio Castracani, pp. 77-78; Machiavelli, "La vita di Castruccio Castracani", p. 301.

${ }^{67}$ Maquiavelo, La vida de Castruccio Castracani, pp. 48-50; Machiavelli, "La vita di Castruccio Castracani", pp. 287-288.

${ }^{68}$ Maquiavelo, La vida de Castruccio Castracani, pp. 45-46; Machiavelli, "La vita di Castruccio Castracani", p. 286. 
mandado matar a un viejo amigo, dice que cuando decidió hacerlo, ya no lo era, era un enemigo nuevo ${ }^{69}$.

Aunque Skinner no termine de afirmarlo explícitamente, cabe remarcar que Machiavelli no predica el abandono de las virtudes cardinales platónicas (prudencia, justicia, templanza, fortaleza). Castruccio no se presenta en exceso afecto a la concupiscencia, aunque es bastante liberal en lo que respecta a la conducta sexual de los ciudadanos de Lucca. No les condena ni por tener amantes sin casarse ni por frecuentar prostíbulos, aunque les recomienda que no entren en esos establecimientos cuando puedan ser vistos. Es prudente, en el sentido astutamente maquiaveliano, no es particularmente injusto y es valiente, en el más clásico de los sentidos. Quizás lo único que puede reprochársele en este último aspecto es que sus ansias de honor y gloria le hacían emprender acciones por demás audaces, sin las cuales, vale decirlo, no hubiese sido un ejemplo de liderazgo militar ni tampoco hubiese ejercido su virtù de manera tal que pudiera doblegar, al menos en el momento final, a la diosa Fortuna. Ciertamente Machiavelli reconoce que no practicar algunas virtudes (especialmente la templaza) puede ser tolerable si no pone en riesgo la supervivencia del stato $^{70}$. En esto, como tantas otras cosas, Castruccio Castracani era un ejemplo a seguir.

Para Skinner este cambio de valoración de las virtudes es una revolución copernicana de Machiavelli. Pero esa revolución no radica en que con el príncipe moderno aparezca un tipo de hombre excepcional sin precedentes. En su visión, si gracias a la fortuna y a cierta pericia de sus fundadores, Roma contaba con leyes (o más precisamente, con un ordine o constitución más cercana a la concepción aristotélica del estado social modernizada por Montesquieu [16891755] en su versión "liberal federalista") y con ciudadanos virtuosos, también necesitaba de líderes con cualidades de mando militar y civil para expandirse y sobrevivir. Por ende, para Skinner no existe un hiato insalvable entre el Machiavelli de El Príncipe y el de los Discorsi, idea que por momentos parece persistir en el análisis de Pocock ${ }^{71}$. Según la interpretación de Skinner, Castruccio no es solo un exemplum virtuoso de príncipe nuevo sino también un líder o caudillo cuya virtud puede servir para impedir la corrupción o el desastre de un stato que ni antes ni después de su paso por el poder abandonó la forma republicana ${ }^{72}$.

\footnotetext{
${ }^{69}$ Maquiavelo, La vida de Castruccio Castracani, p. 76; Machiavelli, "La vita di Castruccio Castracani”, p. 300.

${ }^{70}$ SKINNER, Maquiavelo, p. 119.

${ }^{71}$ Ibid., p. 77.

${ }^{72} \mathrm{Al}$ menos hasta la llegada de Napoleón Bonaparte (1769-1821), que transformó la ciudad en dominio regio de su hermana Elisa (1777-1820) en 1805, Lucca siguió siendo república.
} 
Para Pocock ${ }^{73}$, por su lado, la inversión moral maquiaveliana importa menos por su fidelidad al legado neorromano y estoico que por su impacto en la propia figura del vir, que deja de ser un ciudadano que vive con otros para transformarse en un hombre excepcional bastante próximo al tirano clásico. La muerte del vivere civile es para Machiavelli, al menos en la versión de Pocock, lo peor que puede pasar en política ${ }^{74}$. Y eso solo le pasa a las repúblicas, ya que los príncipes como mucho pueden perder su stato. Aunque si este no es solo el status del príncipe sino también una unidad política, Machiavelli, en su versión protohobbesiana, no lo creería tampoco.

De todas formas, la paradoja radica en que quien mata el vivere civile colectivo al pretender encarnar en uno lo que corresponde a muchos puede, dentro y fuera de las repúblicas, transformarse en su "salvador". Optando por el Machiavelli tradicionalmente republicano, Pocock elude el problema político que sintetizó tan bien la frase de Raymond Aron (1905-1983): "La república temía a tal punto a los grandes hombres que se veía obligada a recurrir, de tanto en tanto, a salvadores" ${ }^{\prime 2}$. Pero Pocock no puede dejar de reconocer que su propia concepción de la virtù "parcialmente no moral" termina hermanando a los hombres de los Discorsi con el gran hombre de El Príncipe ${ }^{76}$. El príncipe impone una forma a la fortuna al alterar los acontecimientos con su propia intervención y rompe con la legitimidad tradicional mientras que los ciudadanos romanos lograron, mediante la institucionalización de la virtud cívica, dotar de estabilidad a las poleis o los stati, cuya materia prima, por su humanidad, es tan voluble. Justamente los liderazgos en la república, sin ser nunca cesaristas ${ }^{77}$, tienen que estar ahí si se quiere garantizar una de las premisas centrales de Machiavelli para explicar la grandeza de Roma: la continuidad en el cambio.

Entonces, cabe preguntarse si en el vivere civile la innovación no puede llegar a través de una figura personal encarnada en un individuo singular. Y si cuando lo hace para bien, su irrupción repara aquello que se había vuelto anacrónico y cuando lo hace para mal, las instituciones heredadas sabrán resistir su poten-

${ }^{73}$ Pocock, El momento maquiavélico, passim.

${ }^{74}$ Ibid., p. 273.

${ }^{75}$ Marcos Novaro, Liderazgos y representación en las democracias contemporáneas, Homo Sapiens, Rosario, 2000, p. 271.

${ }^{76}$ Ibid., p. 272.

${ }^{77}$ Machiavelli es un anticesarista declarado, si por esto se entiende alguien que se opone al tiempo de movilización política que hizo Julio César, inspirado en el mal ejemplo de los Gracos, de la plebe urbana romana. Maquiavelo, Discursos sobre la primera década de Tito Livio, pp. 8688. Eso no impidió que tenga una versión, por momentos, idealizada de otros césares, pero sí devela la tensión que existe en su república popular entre el pueblo y la plebs. 
cia destructora ${ }^{78}$. La respuesta a esa pregunta, que atraviesa toda la obra de Machiavelli, también tiene una respuesta singular en esta nouvelle autobiográfica que el diplomático florentino dedicó al viejo condotiero de Lucca.

Si en La vida de Castruccio Castracani, como casi siempre en los asuntos humanos, la fortuna triunfa, este hecho no testimonia exclusivamente el creciente pesimismo antropológico maquiaveliano. Ese triunfo representa también la posibilidad si no de fundar, esa es tarea del legislador, cuyo élan está en el futuro más que en el presente ${ }^{79}$, sí de comprender cómo el buen político transforma la decisión ocasional en virtud. Y esa virtud no es otra que la institucionalización de un orden político que se estabilice y expanda no por neutralizar sino por cobijar el conflicto que le es co-constitutivo.

Antes de finalizar este apartado nos detendremos brevemente en una cuestión, la relación entre el príncipe o el jefe político-militar en las repúblicas y el pueblo. En La vida de Castruccio Castracani el rol del pueblo se reduce a reconocer las cualidades de su liderazgo en los momentos cruciales, cuando Castruccio asume el mando tras la muerte de Guinigi, tras la conjura de los Poggi, y cuando convoca dos veces su valor para vencer a los florentinos, que eran superiores en número.

Si en El Príncipe Machiavelli aconseja, especialmente a los hombres nuevos de la política, apoyarse antes en el pueblo que en los grandes por su fidelidad, también establece que antes que el amor, lo que debe procurar el príncipe es ser temido para no ser desafiado (aunque debe evitar ser odiado). Es necesario que el pueblo, y más que nada los grandes heridos por haber perdido el control del gobierno que pueden organizar con sus habilidades de zorros el poder popular leonino, teman al príncipe; pero ni al príncipe ni al populo suele bastarles ese vínculo. Esto se explica cuanto menos por dos razones. Primero, el pueblo debe ejercer su facultad de juzgar quién tiene mejores cualidades de mando, especialmente si se trata de una república, pues en un principado el acuerdo tácito protohobbesiano de protego ergo obligo puede funcionar sin ningún aditamento. En eso y en la selección de los grandes lineamientos políticos, incluidos los cambios que un ordine necesita para persistir, es donde el pueblo es mucho más prudente que cualquier grande, como se dice en los Discursos $^{80}$.

\footnotetext{
${ }^{78}$ Althusser ofrece una clara y elocuente conceptualización de la diferencia entre la violencia que repara y la que destruye. Althusser, Politica e Historia, p. 216.

${ }^{79}$ Pocock, El momento maquiavélico, pp. 275-277.

${ }^{80}$ Maquiavelo, Discursos sobre la primera década de Tito Livio, pp. 149-153.
} 
La segunda razón es que el éxito de una comunidad política, sobre todo en términos de política exterior y de defensa, depende de la capacidad de conducción de un liderazgo confiable para una fuerza militar compuesta por ciudadanos-soldados, no profesionales. En su versión romana, más cívica y clásica, o en su versión moderna, más delegativa, los soldados son siempre parte del pueblo y no se conforman a obedecer si esto no significa luchar por una causa valiosa y que quienes demuestran una capacidad de sacrificio igual o mayor a la del líder sean reconocidos por este; una capacidad que incluso puede estar institucionalizada en el caso de las formas políticas más virtuosas, como la devotio consular romana ${ }^{81}$. En ese mundo, como en la New Model Army de Oliver Cromwell (1599-1658), las diferencias jerárquicas del mando no justifican las distinciones a la hora de hacer uso de la palabra pública y actuar a través de ella. Pero cabe preguntarse si esas virtudes del mando y el orden militar pueden trasladarse en la forma de gobierno civil que sea moderna, activa y popular.

Castruccio Castracani impone temor pero también admiración, sabe reconocer las diferencias que una república clásicamente antigua cobija sin servirse de las mismas de manera desigualitaria:

Era de una modestia inestimable, no se le veía realizar acto o decir palabra que no fuese conveniente, y era reverente con los superiores, humilde con los iguales, gentil con los inferiores. Estas cualidades hacían que no solamente toda la familia de los Guinigi, sino la ciudad etera de Lucca, lo amase ${ }^{82}$.

En eso el príncipe nuevo en versión Castracani es muy distinto de aquellos que se imponen despóticamente, a partir de hacer de sus súbditos tan desiguales respecto de él como trágicamente iguales entre ellos. Pero ciertamente no hay en la descripción de Lucca que se presenta en La vida de Castruccio Castracani un análisis de aquellos ordini que posibilitaban una participación activa del populo raso más allá de la acclamatio al líder o la selección de aquellos que tengan las "mejores" cualidades para el ejercicio de las magistraturas. Sin embargo, como puntualiza McCormick ${ }^{83}$, la descripción de esas instituciones como el tribuno de la plebe, las acusaciones, el juicio popular, el veto o la revocatoria, y en algunos casos la dictadura, es central en los Discursos para sostener la hipótesis de que

${ }^{81}$ Sobre la figura de la devotio consular, véase Giorgio Agamben, Homo Sacer: El poder soberano y la nuda vida, Pretextos, Madrid, 2003, pp. 98-106.

${ }^{82}$ Maquiavelo, La vida de Castruccio Castracani, p. 32. Para la versión en italiano véase MaChIAVELl, "La vita di Castruccio Castracani", p. 282.

${ }^{83}$ McCormick, "Machiavelli's Political Trials and The Free Way of Life", pp. 403-408. 
lo que hizo fuerte a la Roma republicana fue el conflicto de clases y no su neutralización. Si bien en la semblanza de Lucca falta una sociología política que permita comprender el contexto institucional y la estructura de clases de esta república y su condotiero ejemplar, persiste la idea fuerza de que liderazgo y república no son contrarios asimétricos, y de allí puede deducirse la idea de que un gobierno popular institucionalizado pero no desacralizado de novedades singulares, pueda hacerlos complementarios.

Sin embargo, hay una cuestión que no puede eludirse. Si bien es posible identificar aquellas instituciones maquiavelianas donde se expresa el gobierno popular en acto y podemos mostrar cómo este último no es incompatible con los liderazgos en tanto y en cuanto estos no reduzcan la relación con el pueblo a la acclamatio, no hay ni en La vida de Castruccio Castracani ni mucho menos en los Discursos una apuesta clara de Machiavelli por el populismo como forma política o estética. Sin entrar aquí en detalles sobre las tensiones internas del populismo, entendida por la confianza en la clarividencia política del pueblo y la valoración estética de los modos de ser de las clases populares, hay que decir que en la obra de Machiavelli la plebs, especialmente la urbana, fácilmente movilizable por las consignas cesaristas, opera como límite ${ }^{84}$. Se trata de un límite político, social y hasta cultural de la versión más democrática de Machiavelli que, como la virtuosamente aristocrática, es falsa si se la postula como radical.

Castruccio tiene otros rasgos más que le hacen ser un personaje singular: su sagaz ironía y su sentido de la autocrítica. Estos rasgos le hacen más maquiaveliano que a cualquiera de los otros príncipes, cónsules o jefes militares que el florentino admiró. Gracias ello, Castruccio se revela como un hombre capaz de

${ }^{84}$ Este "populismo" maquiaveliano o, mejor dicho, para evitar el deslizamiento conceptual, su preferencia por el gobierno popular antes que por la república aristocrática se observa en sus valoraciones de la república veneciana que siendo mucho más estable que la florentina, no es ejemplar ni modélica como lo es la "moderadamente plebeya" Roma anterior al siglo I antes de Cristo. Pero tampoco hay que olvidar que en su versión del sueño de Escipión Machiavelli optaba por pasar la vida ultraterrana en el infierno con los sabios y las figuras políticas del pasado antes que en el cielo con los pobres bienaventurados. PIRES, "Machiavel, la cour des Antiques et (le dialogue) avec Thucydide", p. 59. Es muy interesante remarcar que, a pesar de su "plebeyismo" (en el proemio de El Príncipe destaca la importancia que tiene la perspectiva desde abajo para los de arriba, pero sobre todo la mirada desde arriba, siempre oculta por el arcanum, para los de abajo en la política), Machiavelli es muy crítico de varios de los referentes del partido popular romano. Maquiavelo, El Príncipe, p. 24; Maquiavelo, Discursos sobre la primera década de Tito Livio, pp. 86-88. Quizás Machiavelli, podría aventurarse, tenía más como modelo del sujeto político activo al ciudadano soldado arraigado a la tierra del cordón agrícola que rodea la cité antes que a las "clases populares" urbanas, sin tierra ni dioses tutelares. Sin embargo, en otros momentos, esa misma plebs muestra una extraña clarividencia política. 
saber qué pudo haber hecho mejor para preservar su stato una vez que concluyera su vida biológica (considerará que no debería haberlo ampliado tanto) y qué debió hacer, y lamentablemente no hizo, para lograr una rutinización adecuada de su carisma. Pero sobre todo, esa ironía aplicada a sí mismo se denota cuando el príncipe Castracani reconoce que cualquiera de los ciudadanos de Lucca, que no abandonaron nunca la actitud propia del vivere civile aunque por momentos se comportaron como súbditos, podían darle una lección de vida y de política, dos facetas que al menos para él eran lo mismo. En esas lecciones del pueblo "raso" al líder "popular" Castruccio se revela como prudente y Machiavelli como "populista", si por eso se entiende alguien que cuestiona los criterios de gusto y distinción otorgados por la legitimidad cultural ${ }^{85}$.

¿Este populismo maquiaveliano implica que toda comunidad entre un príncipe y un pueblo conduce al buen camino de la estabilidad de la forma política? Para nada. Machiavelli rechaza las versiones cesaristas del populismo (por su violencia destructora y su condescendencia) y mantiene una valoración positiva de los placeres, incluso más que de las virtudes, que un hombre clásico (vir) debía saber disfrutar. Estos placeres sin una forma política relativamente estable son quiméricos pero, sin una forma política algo cívica, son totalmente prescindibles.

Castruccio, por ser casi un moderno, quizás consciente de la adversidad de la fortuna y de que el tiempo le era poco propicio, no pensó en la posibilidad de transformar el apoyo popular en un poder popular institucionalizado en gobierno que cada vez que la ocasión lo ameritara, supiera reconocer la novedad que el condotiero del futuro viniera a traer. Su biógrafo ciertamente tampoco lo hizo de forma taxativa, pero nos legó conceptos y figuras conceptuales que permiten pensar virtuosamente (en el sentido de la virtù) si no llegó la ocasión de hacerlo.

\section{HACIA UNA CONCEPTUALIZACIÓN DEL GOBIERNO POPULAR}

En esta instancia podemos afirmar que La vida de Castruccio Castracani es un exemplum del arquetípico príncipe maquiaveliano porque presenta un compendio de sus virtudes y un ejercicio pleno de su virtù. También el hecho de haber sucumbido, como hace el propio Machiavelli según el relato de Viroli ${ }^{86}$, a los vaivenes de la fortuna lo transforma en un retrato de un pesimismo antropológico

${ }^{85}$ Seguimos aquí la caracterización sociológica-cultural de Claude GRIGNON y Jean-Claude PASSERON, Lo culto y lo popular. Miserabilismo y populismo en sociología y en literatura, Nueva Visión, Buenos Aires, 1991.

${ }^{86}$ Viroli, La sonrisa de Maquiavelo, p. 306-307; VIroli, Il sorriso di Niccolò, p. 254. 
maquiaveliano que no hace sino crecer con los años. La oración fúnebre de Castruccio al morir enfermo de fiebre tras su última batalla, no obstante, nos permite pensar que la consciencia de su error puede servir de exemplum a futuros príncipes para no cometerlo de nuevo. Igualmente esa consciencia virtuosa no impide que la vida de Castruccio, como toda vida que se precie de buena, termine mal y a destiempo.

En el marco de nuestra investigación nos interesan otras dimensiones de esa ejemplaridad de La vida de Castruccio Castracani.

Primero, con esta versión de El príncipe, escrita después que los Discorsi, Machiavelli deja en claro nuevamente que no hay una absoluta incompatibilidad entre la república como forma política y el liderazgo. Y esto sucede tanto en el caso de Roma, modelo político por excelencia, como en el mucho menos ejemplar caso de Lucca, que a pesar de sus defectos está más cerca de la estima maquiaveliana que la aristocrática Venecia. Una buena república es una combinación entre la estabilidad y la expansión, y para que ello sea posible, tiene que haber lugar para el cambio. Y ese cambio, al menos en los tiempos modernos o tardo-medievales que a Machiavelli y Castruccio les tocó vivir, suele venir encarnado en una figura personal singular. En este punto, y en un texto casi ignorado por el propio historiador inglés, la hipótesis de Skinner sobre la continuidad conceptual entre El Príncipe y los Discorsi no pierde vigor.

Segundo, el príncipe nuevo encarna la novedad política en su figura personal. Este elemento innovador y expansionista de la virtù maquiaveliana encuentra en Castracani un caso singular que combina cosas antiguas, como el origen oscuro, con cosas modernas, como el contexto tardo-medieval donde se sitúa su vida y los príncipes con los que se le compara. Pero también en esta historia Machiavelli dota al pueblo de un rol similar al de la fortuna en su capacidad de elegir a un príncipe y juzgar sus capacidades. Ciertamente a diferencia de los ordine romanos, con su constitución mixta, su sistema electoral y sus instituciones antioligárquicas, la participación popular en la vida política de Castracani se limitaba a la acclamatio o el reconocimiento de las cualidades del príncipe y a conformar las milicias ciudadanas que toda comunidad política que se precie requiere para no perecer en manos de ejércitos sin compromiso patriótico. Así pues, más allá de ser una fuerza necesaria para la organización militar, el pueblo de Lucca no parecía ser demasiado activo. ¿Cómo transformar ese poder popular para que pueda convertirse en acción y de esa manera no mueran ni el vivere civile republicano ni la democracia que no es concebida exclusivamente como delegativa y representativa?

Para responder la pregunta anterior se puede volver al planteo crítico de McCormick sobre la lectura neorrepublicana de Machiavelli y así abordar la 
cuarta dimensión que se destaca en esta interpretación de La vida de Castruccio Castracani: el carácter popular del republicanismo maquiaveliano. Para que la república no termine, por liberal o por aristocrática, por formalista o por clasista, siendo despopularizada es necesario recordar que la forma de gobierno del pueblo que Machiavelli reivindica es a la vez participativa e institucionalista y no rechaza la innovación política, incluso cuando esta llegue a través de un personaje singular. Desde allí el gobierno popular es algo más que un sinónimo del gobierno representativo, la democracia liberal y la república moderna, pero no es refractario a la institucionalidad, si por esta se entiende algo más que un mecanismo de selección de liderazgos o un formalismo jurídico. En este sentido coincidimos con la crítica de $\mathrm{McCormick}^{87}$ al republicanismo que termina siendo funcional a una versión mínima de la democracia o el gobierno representativo pero preferimos, a diferencia de él, rescatar lo popular en Machiavelli antes que el populismo por las derivaciones que ha tenido este concepto en el debate teórico y la práctica política de las democracias contemporáneas, especialmente en América Latina.

Machiavelli, como reconoce el propio McCormick, favorece esta elección cuando hace de la siguiente frase, donde compara el Gran Consejo de Florencia con la Guardia de los ocho, el núcleo argumental de su teoría del gobierno popular:

Pero después de cambiar este orden por mutación del estado ${ }^{88}$, crearon ocho ciudadanos para que ejercieran el oficio del antiguo enviado ${ }^{89} \mathrm{y}$ así el procedimiento, de malo que era, se convirtió en pésimo, por lo que decíamos antes de que los pocos son partidarios de los pocos y los poderosos ${ }^{90}$.

${ }^{87}$ McCoRmick, "Machiavelli Against Republicanism”, pp. 615-618, 637.

${ }^{88}$ Se refiere a que Florencia pasó de ser un ciudad sierva del extranjero a ser una ciudad libre.

${ }^{89}$ Se refiere a la apelación de una sentencia, oficio que de ser ejercido por un príncipe pasó a estar en manos de una elite.

${ }^{90}$ Maquiavelo, Discursos sobre la Primera década de Tito Livio, p.156. En el libro I cap. 49 de los Discorsi compara las instituciones romanas, los juicios populares y el rol del dictador como tribunal de apelación con los juicios de las ciudades italianas donde todo quedaba en manos de las elites. En la Historia de Florencia va a demostrar que el equilibrio entre el poder popular y los pocos es imposible no por la desunión de la ciudad (cosa que en Roma funcionaba de manera virtuosa) sino porque ambos grupos cuando tenían el poder no pretendían controlar al otro sino destruirlo. Maquiavelo, Historia de Florencia, pp. 205-207. Recordemos que también en los Discorsi Machiavelli critica a Girolamo Savonarola (1452-1498) por haber juzgado a los que conspiraron contra él en forma cerrada, sin tribunales populares ni otras formas de apelación. MAQUIAVELO, Discursos sobre la Primera década de Tito Livio, p. 146. 
Esto es posible porque para Machiavelli la república no es el gobierno de pequeños comités sino el gobierno del pueblo entre cuyas virtudes está saber qué hacer para conservar lo stato, reconociendo cuándo y cómo debe confiar esa misión a una figura singular y cuándo retirarle institucionalmente esa confianza, sin renunciar nunca al compromiso activo en la vida política y su gobierno. Y todo eso lo hace Machiavelli sin dejar de ser un republicano. Lo que ocurre es que es republicano de una manera innovadoramente singular e institucionalmente popular.

En conclusión, desde la cosmovisión maquiaveliana presentada en este artículo no se consideran incompatibles ni la república con el liderazgo, ni la novedad fundacional con la institucionalización, ni el reconocimiento de la necesidad y el magnetismo del poder personal con la vida política activa por parte del pueblo.

No puede decirse que exista en la Teoría Política de Machiavelli una conceptualización que permita transformar estas antinomias (poder personal e instituciones, innovación individual y poder popular) en convergentes. Pero sí existe la posibilidad de encontrarla a partir del estudio de sus exempla. Reflexionando a partir de ellos, y tomando a Castracani como arquetipo, podemos concluir que es factible pensar una categoría de gobierno popular que recupere la dimensión institucionalista del republicanismo, desde una perspectiva no formalista sino histórica, y que a la vez se apropie del liderazgo personal del principado para innovar políticamente toda vez que sea necesario.

El gran desafío es lograr que esa violencia necesariamente reparadora y fundante no devenga en destructora de la comunidad política cuyo sentido histórico se valora. Lo que se pretende es encontrar un ordine que no opere como muro de contención de aquello que desde un punto de vista conservador se quiere evitar (el populismo en sus versiones cesaristas o democrático-participativas à la Pettit, la democracia plebiscitaria) sino que sea la condición de posibilidad para los cambios conceptuales y políticos por venir. 